\title{
Mestrado Nacional Profissional em Ensino de Física: uma história de sucesso; um futuro promissor
}

National Professional Master's Degree in Physics Teaching: a successful story; a promising future

\author{
Iramaia Jorge Cabral de Paulo*1], Rita M.C. de Almeida ${ }^{2,3,4}$ \\ ${ }^{1}$ Universidade Federal do Mato Grosso, Instituto de Física, Cuiabá, MT, Brasil. \\ ${ }^{2}$ Universidade Federal do Rio Grande do Sul, Instituto de Física, Porto Alegre, RS, Brasil. \\ ${ }^{3}$ Centro Brasileiro de Pesquisas Físicas, Instituto Nacional de Ciência e Tecnologia de Sistemas Complexos, \\ Rio de Janeiro, RJ, Brasil. \\ ${ }^{4}$ Universidade Federal do Rio Grande do Norte, Natal, RN, Brasil.
}

Recebido em 08 de novembro de 2021. Aceito em 09 de novembro de 2021.

Esta Nota ao Editor tem por objetivo reportar o atual estado e divulgar uma iniciativa da Sociedade Brasileira de Física (SBF) que visa melhorar o ensino de Física na Educação básica brasileira: o Mestrado Nacional Profissional em Ensino de Física (MNPEF). Pretende também discutir as raízes do sucesso desta ação, além de apontar desafios atuais, ações para tratar dos desafios e descrever os planos futuros.

Palavras-chave: Mestrado Nacional Profissional em Ensino de Física - MNPEF, formação de Professores, ensino de Física, educação básica.

This Note to the Editor reports the current status of a Brazilian Society of Physics (SBF) initiative that aims to improve the teaching of Physics in Brazilian school: the National Professional Master in Physics Education (MNPEF). It also intends to discuss the roots of the success of this action, in addition to pointing out current challenges, proposing actions to address these challenges and laying out future plans.

Keywords: National Professional Master's Degree in Physics Teaching - MNPEF, formation of teachers, physics teaching, basic education.

\section{O Mestrado Nacional Profissional em Ensino de Física}

Esta Carta ao Editor leva ao conhecimento do público, um panorama da história e evolução do Mestrado Nacional Profissional em Ensino de Física (MNPEF) que completa, em 2021, 8 anos e forma uma rede nacional envolvendo 58 instituições públicas de ensino superior. Trata-se de uma ação da Sociedade Brasileira de Física (SBF) que compõe o Programa de Mestrado Profissional para Qualificação de Professores da Rede Pública de Educação Básica (PROEB), fomentado e avaliado pela Coordenação de Aperfeiçoamento de Pessoal de Nível Superior (Capes).

Pode-se assegurar que é a maior ação de cientistas brasileiros atuando em larga escala diretamente na Educação Básica, em parceria com colegas professores que atuam nessa etapa do ensino da Física.

Duas razões podem ser atribuídas à consolidação do Programa: uma dinâmica administrativa bem estabelecida, mas em constante avaliação que permite detectar enfrentar rapidamente os problemas cotidianos, como por exemplo, os recentes desdobramentos da pandemia

\footnotetext{
*Endereço de correspondência: iramaiaj@gmail.com
}

causada pelo COVID-19 no país que nos levou a propor medidas para minimizar os impactos de uma possível desmobilização nos polos do MNPEF e o imprescindível fomento da cultura de interlocução entre a academia e as salas de aula da Educação Básica.

Além de descrever a estrutura do MNPEF, que lhe confere o sucesso alcançado até aqui, pretendemos apontar desafios atuais, ações para tratar dos desafios e descrever os planos futuros.

\section{A Estrutura do MNPEF}

O MNPEF iniciou suas atividades em 2013, tendo sido resultado de uma colaboração da diretoria à época da SBF com a Coordenadoria de Aperfeiçoamento de Pessoal de Ensino Superior (CAPES) para a montagem deste projeto. O MNPEF é um mestrado em rede, voltado para professores de Física ou áreas afins em exercício em sala de aula da Educação Básica do país, ministrado em polos do MNPEF que são hospedados por Instituições de Ensino Superior (IES) públicas.

O título de mestre é outorgado pela IES que hospeda o polo e para recebê-lo, o mestrando deve ter cursado disciplinas obrigatórias e optativas, ter redigido uma dissertação e conjuntamente elaborado um produto educacional, testado em sala de aula 
e disponibilizado publicamente nos repositórios do MNPEF-SBF e CAPES.

Nestes 8 anos o MNPEF passou dos 21 polos iniciais para os atuais 58 polos, estando presente em 24 estados e no Distrito Federal, com sedes em centros urbanos como o Rio de Janeiro e na grande São Paulo, em localidades não centrais, no coração da Amazônia ou do Cerrado, como Barra do Garças, e Ji-Paraná, bem como no semiárido sertão nordestino, como o Crato no Cariri Cearense e em Mossoró no Rio Grande do Norte. Inicialmente contávamos com 212 docentes, e hoje temos 996 docentes, todos doutores, e com especialidades que abrangem Educação e Ensino de Física ou Ciências $(12 \%)$ e as diferentes áreas da Física (88\%).

Já formamos até o momento 1680 mestres, com os 1680 produtos educacionais já disponibilizados e no momento presente temos 1580 discentes ativos. Todos os produtos educacionais (que podem ser de diferentes formatos: sequência didática, aplicativos, montagem de experimentos com Arduino e com materiais alternativos etc.) devem ser necessariamente planejados e fundamentados em alguma teoria de aprendizagem e metodologias bem estabelecidas na literatura e devem ser testados em sala de aula. A dispersão dos polos pelo território nacional, embora muito desejável, implica em heterogeneidade de condições. As disciplinas, dissertações e produtos passam todos por um crivo da Comissão de Pós-Graduação Nacional (CPG-Nacional) antes de serem submetidas a bancas acadêmicas, garantindo que os requisitos mínimos exigidos pela CPG-Nacional sejam atendidos de maneira homogênea por todos os polos.

Os custos de uma ação de tal monta vem de um aproveitamento importante da infra-estrutura das IES pública (salários de todos docentes, infra-estrutura física, laboratórios de ensino são financiados pelas IES), da SBF (infra-estrutura para o funcionamento e administração da CPG-Nacional) de tal maneira que a verba específica que o MNPEF recebe da CAPES é quase que inteiramente destinada às visitas ao polos, financiamento de bolsas de mestrado para cerca de $30 \%$ dos discentes, financiamento de realização de mostras e simpósios, financiamento de alguns produtos educacionais, além de garantir reuniões presencias da CPG-Nacional.

\section{As Razões do Sucesso do MNPEF}

Além de obrigação de prestarmos conta aos sócios da SBF e à comunidade em geral, detectamos a necessidade de expormos as razões do sucesso do MNPEF. No país há diferentes comunidades com o mesmo objetivo de contribuir para melhorar o ensino da Física. A despeito das diversas perspectivas, o MNPEF traz uma proposta de pesquisa aplicada ou translacional, onde o conhecimento construído na pesquisa básica é um referencial importante. Durante os 8 anos do MNPEF, muito se aprendeu e hoje temos já uma tecnologia de gestão acadêmica que é resultado dos erros e acertos. Podemos servir como evidência para resolver controvérsias geradas talvez pela diversidade dos docentes e pesquisadores que atuam ou se interessam pela Educação básica e ou pelo ensino da Física. Apontamos como fundamentais para o sucesso do MNPEF os fatores seguintes:

\subsection{Disciplinas formativas abordam teorias de física em nível de mestrado}

A formação do professor de física não pode se limitar às físicas gerais dos semestres iniciais da graduação. Isso porque a Educação Básica nos dias atuais tem que fazer frente às demandas e uma sociedade altamente tecnológica, cujos conteúdos têm que ser constantemente remodelados. O Professor de Física da Educação básica tem que ser capaz de compreender os avanços da Ciência e da Tecnologia com profundidade suficiente para traduzir para seus alunos, não podendo somente repetir a Educação básica que ele cursou. O MNPEF é uma evidência de que essa formação é possível em escala ampla.

\subsection{Disciplina formativa abordando teorias de aprendizagem}

Através dos fundamentos teóricos de aprendizagem, o professor de Física passa a conhecer como o sujeito aprende o que lhe confere capacidade de formular produtos educacionais e sequências didáticas novas, a partir de conteúdos novos. Conteúdos que são abordados em sala de aula há décadas já contam com abordagens já testadas e discutidas. Os novos conteúdos, não. O professor de Física tem que ser capaz de propor, aplicar e testar a eficiência de produtos educacionais. A experiência do MNPEF evidencia que aliar a formação em Física à formação em Ensino além de possível, é condição sine qua non para o sucesso de um mestrado profissional em escala nacional.

\subsection{Produto educacional}

A exigência do produto educacional, bem como a validação do mesmo em sala de aula visa pôr em prática os conhecimentos adquiridos nas disciplinas formativas (relacionadas com a Física e teorias de aprendizagem). Este é um mestrado de cunho profissional e, assim, a habilitação do egresso na prática da profissão se faz necessária. O requisito que esse produto seja disponibilizado publicamente visa a formação de um Acervo Nacional de Produtos Educacionais, uma infraestrutura nacional necessária e bem-vinda.

\subsection{Dissertação}

A exigência da dissertação visa a vivência acadêmica do mestrando, aproximando-o da linguagem desenvolvida nas Universidades e habilitando-o para uma interação com os meios acadêmicos de forma contínua. Diferentemente de outros profissionais, a convivência em 
meios acadêmicos para um professor da Educação Básica torna-se cada vez mais necessária numa sociedade que avança tão rapidamente em Ciência e Tecnologia.

\subsection{Gestão acadêmica}

O MNPEF, devido à sua escala abrangente e nacional, é único no mundo, portanto a gestão acadêmica foi construída ab initio. Dada a heterogeneidade do País, a formação de uma CPG-Nacional garante requisitos mínimos a todas as dissertações, produtos e disciplinas. Os polos são periodicamente visitados por integrantes da CPG-Nacional, com uma avaliação que considera além da infraestrutura local, as manifestações do coordenador do polo, dos docentes, dos discentes [1. Serve também como via para as demandas do polo e detecção de problemas que exigem mudanças de rumo. A CPG-Nacional também avalia as dissertações e produtos para então liberá-los para a submissão a uma banca acadêmica. A formação das bancas sugeridas pelos polos deve ser aprovada pela CPG-Nacional. Dada a escala do MNPEF (1580 discentes ativos), todo esse controle é possível pela construção de uma plataforma digital customizada. Estas atividades, com seus procedimentos já estabelecidos e documentados, formam uma tecnologia de gestão e de boa governança que tem possibilitado a escalabilidade do MNPEF.

\section{Os Desafios Atuais do MNPEF e Nossas Ações para Enfrentá-los}

Enfrentamos diferentes tipos de desafios, como segue:

\subsection{Avaliação de impacto}

Embora tenhamos fortes indicadores do bom desempenho do nosso mestrado, uma avaliação independente e que leve em conta o impacto na sociedade em geral deve ser quantitativamente levado a cabo. A avaliação da CAPES que estamos submetidos é periódica e tem sua validade inquestionada, entretanto, não avalia quanto ao impacto do MNPEF sobre a sociedade em geral. "A diferença é que enquanto as métricas de resultados são avaliadas pelos pares, as de impacto incluem os pares, mas também os usuários dos serviços e os beneficiários do conhecimento" [2]. A informação coletada servirá para nortear nossos passos futuros, melhorar a governança, bem como para informar às agências governamentais sobre a eficácia de tais medidas. Como avaliação do impacto consideramos aquela que mede a melhoria do aprendizado dos alunos do ensino fundamental por conta da melhor formação dos professores da Educação Básica, proporcionada pelo MNPEF. Trata-se de uma avaliação multinível onde estão previstas entrevistas em escolas e com alunos do ensino médio, em amostragem que respeite as diferentes realidades dos polos. Dada a escala e a inovação do MNPEF, esta avaliação requer profissionais com boa formação acadêmica e uma instituição com credibilidade que conta com uma equipe de profissionais liderada com doutores. Considerando a inovação deste tipo de avaliação, a equipe prevê como resultado adicional a publicação de artigos acadêmicos. Os recursos para esta avaliação já foram aprovados pela CAPES.

\subsection{Melhor divulgação}

O MNPEF necessita ser mais bem divulgado entre os Físicos, entre a comunidade de profissionais ligada ao Educação Básica do País, bem como na sociedade em geral. Cada uma destas comunidades requer diferentes estratégias de comunicação. Esta Nota ao Editor é uma primeira ação para divulgar o MNPEF entre Físicos e Professores de Física. Divulgação do MNPEF nos encontros promovidos pela SBF, não se restringindo àqueles cujo público-alvo são especificamente relacionados ao ensino (SNEF e EPEF), seria uma ferramenta benvinda, mas que ainda depende da aprovação da diretoria da SBF e das comissões de área, responsáveis pelos encontros. A divulgação entre a sociedade em geral requer um maior entendimento de como fazer isso, tratase de desafio a ser enfrentado em conjunto pelo Conselho do MNPEF e a CPG-Nacional.

\subsection{Procurar maior adesão por parte das Secretarias Estaduais de Educação}

Ação junto às Secretarias de Educação Estaduais. Os nossos discentes são na sua maioria, docentes da Escola Pública Estadual. Para a obtenção do grau de Mestre, é exigido que estejam em atividade em sala de aula durante o mestrado, exatamente porque os produtos são testados e validados em sala de aula e a aplicação das habilidades adquiridas pelos mestres do MNPEF são ainda mais consolidadas, visando a continuidade de criação de produtos educacionais futuras. Neste sentido, os professores têm tido dificuldades de conseguir liberação parcial de carga horária para dedicarem-se ao mestrado, resultando em sacrifícios que nem todos podem ou querem passar. Uma aderência por parte das Secretarias neste sentido ao nosso e aos outros mestrados profissionais em Ensino faz-se necessária.

\subsection{Fomentar a formação de uma comunidade de Físicos Professores na SBF}

Ações voltadas ao ensino tanto na SBF como na comunidade em geral abrangem uma comunidade muito maior que a comunidade de Pesquisa em Ensino de Física. Exemplos na SBF são o próprio MNPEF, onde aproximadamente $12 \%$ dos seus quase mil docentes têm formação strictu senso relacionada com Ensino de Física ou Educação. Avaliamos esta situação como excepcionalmente boa, dado que a colaboração com estes $12 \%$ já garante que todo e qualquer produto e 
dissertação do MNPEF iniciam com a definição da teoria de aprendizagem sobre a qual são construídos [3]. No entanto a ação destes profissionais que vamos chamar de Físicos Professores tem muito em comum, mas que dentro da SBF não têm um espaço especialmente dedicado. Mais ainda, dado que nos últimos 8 anos os docentes da Educação Básica que receberam um grau de Mestrado Profissional em Ensino de Física relacionado como MNPEF (1680 egressos) representam da ordem de $90 \%$ do total, consideramos que o MNPEF agrega informação importante a respeito do ensino da Física acontecendo agora no País e a respeito da realidade enfrentada pelo Professor de Física da Educação Básica. Tal base de dados gostaríamos de compartilhar com todos os sócios da SBF interessados em ensino da Física. Adicionalmente, este conhecimento fortemente baseado em dados reais, aliado com a perpectiva ímpar que Físicos detêm sobre os avanços de Ciência e Tecnologia pode contribuir sugerindo diretrizes para os cursos de formação de professores.

Além das contribuições que uma comunidade de Físicos Professores acima mencionadas, tal comunidade representaria uma atração real e honestamente fundamentada para que os Professores de Física da Educação Básica participem ativamente da SBF, interagindo intimamente com a comunidade de cientistas interessados em ensino, afastando a possibilidade de um cisma entre essas comunidades o quê, na nossa opinião, não traria benefícios ao País (vide o caso dos EUA). Esta ação ficaria a cargo do Conselho do MNPEF e ainda aguarda ser proposta e então amplamente discutida.

\subsection{Interação com os outros Mestrados Profissionais em Ensino}

Além da aderência das Secretarias existem outros pontos que merecem a atenção dos mestrados profissionais, não somente o MNPEF. Assim, está na hora de criarmos um foro destes mestrados profissionais em Ensino, independente de CAPES e MEC, para podermos atuar para melhorarmos as condições em geral destes mestrados.

\section{Considerações Finais: O Que Esperamos para o Futuro}

Para o futuro imediato, esperamos expandir nossa rede, integrar a comunidade de Pesquisa em Ensino e os Físicos Cientistas interessados em ensino, expandir a base de sócios Professores da Educação básica visando formar a comunidade de Físicos Professores capaz de sugerir diretrizes de formação de Professores, implementar as melhorias sugeridas pela análise de dados quantitativos produzidos por uma avaliação de impacto ampla, planejada e realizada seguindo métodos científicos, divulgar com maior eficiência os resultados do MNPEF e iniciar a criação de um foro de mestrados profissionais em Ensino nas diferentes áreas.
Para um futuro a longo prazo, consideramos que Ensino de Ciências em geral, e o de Física em particular, é de interesse da Nação e deve consistir em políticas de Estado e não somente de Governo. Para tal, o ensino da Física tem que ser pensado e suas estratégias planejadas por uma comunidade especialmente dedicada, capaz de se auto-renovar constantemente pela criação de novos quadros e se defender de propostas equivocadas governamentais. A Ciência é um caso parecido e a comunidade atual dos cientistas brasileiros ao longo de décadas vem defendendo com sucesso os avanços da Pesquisa, Pós-graduação e sistema de avaliação por pares. Conta com uma comunidade generosa, no tocante do trabalho adicional imposto, realizado a custo virtualmente zero, e altamente qualificada, participando em nível internacional dos avanços científicos e tecnológicos mundiais. Gostaríamos que o mesmo fosse verdade no que tange o Ensino de Ciências.

Para atingir essa meta é condição imperativa a formação de uma comunidade de pessoas generosas e qualificadas dedicada ao Ensino de Ciências. Na nossa opinião, essa comunidade deve forçosamente englobar os Professores da Educação básica, de forma integrada com os Cientistas preocupados com Ensino.

A meta é ambiciosa e de longe extrapola os limites do MNPEF. No entanto, dados nossos resultados, o ímpeto gerado pelo MNPEF é importante qualitativa e quantitativamente. Por exemplo, já nos permite realisticamente enfrentar os desafios citados acima que contribuirão de maneira significativa para esta meta. O caminho é longo, mas o início de qualquer jornada sempre se dá com um primeiro passo.

\section{Referências}

[1] J.C.I. Paulo, Revista Brasileira em Ensino de Física (2021), não publicado.

[2] J. Marcovivich, Universidades Brasileiras precisam medir impacto, dizem especialistas, disponível em: http://www. jornaldaciencia.org.br/universidades-brasileiras-preci sam-medir-impacto-dizem-especialistas/, acessado em $03 / 11 / 2021$

[3] M. Ferreira, H. Sacerdote, N. Studart e O. L. Da Silva Filho, Revista Brasileira de Ensino de Física 43, e20210322 (2021) 